\title{
IN DEFENSE OF SCIENCE, THE PRESS AND EXPERTISE FOR THE PUBLIC GOOD
}

\section{INTRODUCTION}

Two contradictory phenomena are happening within media discourse. The first is the rapid rise of the Internet and social media, which has vastly increased the reach of ideas. At the same time, because of search tracking and the revenue models of social media such as click through ads, people are increasingly isolated within narrow thought collectives, only receiving information tailored to their indicated interests and viewpoints. Truth becomes more elusive, and not in a fun, playful postmodern way (DeVega, 2017). The interaction of these two aspects has shaped how people approach truth and reality, creating openings for those in power to exploit vulnerabilities (Illing, 2017a; Pomeranstev \& Weiss, 2014; Starbird, 2017).

Once viewed as democratizing and liberating, it has become clear that the Internet and social media are just as subject to the ruling ideas of the capitalist class as any other endeavor. Pomeranstev and Weiss (2014) note that political leaders no longer have to rely on manifest oppression, they can "manipulate from the inside" by exploiting "the idea that 'truth' is a lost cause and that reality is essentially malleable" (p. 17). Because the Internet facilitates the distribution of copies of copies without much fact checking, it is fertile soil for these efforts. Additionally, the data produced from interactions on the Internet has caught the attention of private companies who regularly contract with governments, corporations, political campaigns, etc. to analyze such data to optimize influencing (Shaw, 2018).

The power of the "big lie" that is often attributed to Hitler and Goebbels has far outgrown its original constraints, such as they were. In the past, propaganda would be distributed with a specific message or set of ideas meant to shape public perception. Today, the lie itself is the goal:

We live in a time when intentional, systematic, destabilizing lying — totalitarian lying for the sake of lying, lying as a way to assert or capture political powerhas become the dominant factor in public life in Russia, the United States, Great Britain, and many other countries in the world...engaging with these lies is unavoidable and even necessary. (Gessen, 2018, para. 15)

It is fast becoming clear that even efforts at using leftist alternative media have not been able to penetrate "how information is shared and consumed, and, more 
profoundly...how narratives around that information are shaped and by whom" (Starbird, 2017, p. 1).

In the recent past, concepts that were considered too outlandish and unacceptable for mainstream journalistic discourse have now been given a hearing in those venues. As Goldberg (2018) notes, "an opinion section that truly captured the currents of thought shaping our politics today might include Alex Jones, the conspiracy-mad Sandy Hook truther; the white nationalist Richard Spencer; and CliffsNotes fascist Steve Bannon" (para. 11). This is the culmination of "the coming of a networked society" much heralded by the left in the early days of the Internet, where traditional journalism would be unseated by more democratically produced, leaderless crowdsourcing and just-in-time-content (Nagle, 2017a, p. 3). Unfortunately, "this network has indeed arrived, but it has helped to take the right, not the left, to power" (p. 27). In all of the excitement over the Internet, people failed to see that the content of what was being distributed does indeed matter.

Added to this is a profound dialectical-materialist disconnect between people and the views that they hold. This starts with a misunderstanding about the source of one's beliefs, which do not simply originate within one's self apart from external factors:

An individual's ideology doesn't come from inside them, but is an effect of time and place. But it's much easier to understand how this was true of some stranger in the distant past than to accept it about yourself-that you're a product of the social processes of your time, and your ideas are not crystals of pure rationality, but the residue of these processes. (Winant, 2017, para. 1)

An example of this is the lack of political engagement about the very beliefs that people claim to have, which leads to not being politically informed. When asked to situate themselves along a continuum of government providing more social services on the left to reducing spending on the right, $15 \%$ of respondents declined to answer because "they have not thought about it" (The Power of Groupthink, 2017, para. 8). The same percentage will indicate where they appear on the continuum, but are not able to correctly place Democratic or Republican party platforms. This means one third of the electorate has a profound misunderstanding where the politicians they vote for stand regarding the role of the state (para. 4).

At this point it should be pretty clear that we have moved far beyond Karl Rove's Bush-era declaration of an empire creating its own reality into there being no reality at all unless it meets the approval of Trump and his supporters:

Trumpland...knows no national loyalties and recognizes no transcendent or democratic values beyond power and profit. Trumpland is post-truth and lives on the propagation of fake news. For Donald Trump himself, discourse serves the interests of Trumpland and has no relation to truth and falsity. (Kellner, 2017, p. 100) 
At the same time, much of the left clings to the futile hope that simply repeating facts at the right wing will disrupt their efforts at misinformation (Cloud, 2018). This chapter presents five primary ways that the right wing has attempted to manage perceptions related to their dismantling of the public good and eroding rational thought. These include an attack on the notion of expertise, reviving pseudoscience around race and gender, manufacturing fake news, promulgating both-sides-ism in the press and intensifying the spread of conspiracy theories.

\section{ATTACK ON EXPERTISE}

As discussed in Chapter 2, anti-intellectualism has long been a hallmark of rightwing populist and fascist movements. However, rightist discourse has more recently moved into a more intense focus on a particular facet of intellectualism: expertise (DeVega, 2017; T. Nichols, 2017). Trump and his supporters regularly portray experts as elitist, out of touch, and purveyors of leftist bias. Experts are bogged down by an adherence to tedious, time-wasting details when what is needed is a man (it is always a man) who will get down to business. Dworkin (2017) includes an excerpt from a right-wing blog which encapsulates this hostility toward expertise:

Trump is slaying sacred cows... The only thing anybody knows is that the things we are seeing have never been done before and Donald Trump is refusing to follow any of the proper conventions... Think of the glory of it all. This is the fight we have been waiting for. This is the turmoil we need. The president is making common sense policy decisions that don't need the backing of long reports authored by "experts"...It is almost as if he thinks the people should rule, not supposed expertise... This will undoubtedly result in pushback from bureaucrats and "experts," and timid culture warriors who apparently enjoy self-emasculation or have realized (incorrectly) that they have more to gain from maintaining the status quo. (para. 11)

What this blog post illustrates is that the right-wing view of expertise is also highly gendered, with common sense and "gut instinct" being masculinized, and experts relegated to the realm of the feminized. Disruption is also valued, especially if it stops experts who spend too much time thinking when they should be acting - in right-wing directions, of course. The irony is that while the right-wing continually complains about overly sensitive liberals, their discourse runs entirely on appeals to emotion, such as the talking points surrounding Brexit in 2016. Despite warnings from economists, proponents of England remaining in the EU were portrayed as "enemies of the ordinary voter" or fearmongers (T. Nichols, 2017, p. 209). Michal Gove, one of the key figures behind the Brexit movement, "argued that facts were not as important as the feelings of the British voter" (p. 209).

It is also contradictory that expertise is seen as being out of touch with reality, when what expertise involves is a series of reflections on lived experiences and integrating those reflections into one's practice and existing set of content 
knowledge (T. Nichols, 2017). This is the key difference for the right-experience is rarely reflected upon - and it becomes a form of dogma which reinforces existing prejudices. The idea is to barge ahead and act in-the-moment with the resolve of a heat-seeking missile.

Within anti-expertise frameworks, the mediocre is elevated and becomes a celebrated value. Sartre's (1976) analysis of anti-Semitism found that its antiintellectual adherents, far from being humble and "just regular folks," were the embodiment of arrogance: "there is a passionate pride among the mediocre, and anti-Semitism is an attempt to give value to mediocrity as such, to create an elite of the ordinary. To the anti-Semite, intelligence is Jewish; he can thus disdain it" (p. 16). Dorfman (2017) sees the Trump administration as equating expertise with liberalism. Therefore, experts are replaced by "know-nothing fundamentalists" who represent industry and seek to defund public programs and agencies (para. 6). As T. Nichols (2017) notes, "the public space is increasingly dominated by a loose assortment of poorly informed people, many of them autodidacts who are disdainful of formal education and dismissive of experience" (p. 14).

Under these conditions, the nature of education itself is radically altered, where patriarchal hierarchies are valorized and expressed in narrow, all-male terms. Loyalty, in particular, is held above all other values, with curriculum and messaging stressing concepts like reverence and respect for those holding the appropriate values, over time-tested expertise (Theweleit, 2010b). Sartre (1976) sees this as a manifestation of "a longing for impenetrability" that is held up as an important personality characteristic (p. 12). The anti-expert has to develop this survival strategy in order to "choose to reason falsely" (p. 12). Sartre locates the fear of truth not in the content of that truth (what is usually dismissed as unimportant), but in the various forms that truth can take, which are harder to control.

The attack against experts is accompanied by a resentment of any type of oversight, which is built into professional structures and credentialing. Though imperfect, these protective structures exist to maintain the integrity of the profession and to ensure that ethical standards are being met (T. Nichols, 2017). Jones (2015) relates the views of education privatizer Wendy Kopp, founder of Teach for America when asked to comment on hiring less-experienced teachers instead of veteran ones:

There's also a power in inexperience - that it can make a huge difference to channel the energy of young people, before they know what's "impossible" and when they still have endless energy, against a problem that many have long since given up on. They can set and meet goals that seem impossible to others who know more about how the world works. (p. 81)

It is important to note, however, that right-wing resentment of professionals is not applied to conservative wealthy people (DeVega, 2017). Combined with the disdain for professional expertise is a desire to aspire to be rich and ambitious, but still retain one's folksy, populist values. 
Part of what contributes to a hostility toward experts is that much of the systematic problem-solving processes they use are not easily seen and can be shrouded in mystery. T. Nichols (2107) points out how the multiple revisions that are part of professional communities take place outside of the public eye where all that is visible is the final result. And even then, it's not as apparent unless something malfunctions. In the case of repealing the Affordable Care Act, it is difficult for people to conceptualize the degree of economic impacts that a repeal could have, even if they have some vague ideas. Society is also structured in such a way that people are alienated from the processes that produce most of the artifacts of modern life. This can lead people to think, "how hard can that be?" when contemplating the role of expertise (para. 13). A lack of transparency also applies to how projects like think tanks are funded and the impact of the private sector on shaping laws (Pomeranstev \& Weiss, 2014). It is no surprise that political leaders take advantage of an overall lack of political knowledge to create messaging in support of right-wing ideas like Brexit that fall apart under scrutiny (T. Nichols, 2017).

There is also a cognitive aspect to anti-expertise thinking, involving confirmation bias and reasoning shortcuts (Ehrenreich, 2017; T. Nichols, 2017). All people, including experts, have to grapple with how to explain phenomena and start with a set of assumptions; otherwise nothing would get done. While strategies like shortcuts can assist with decision-making, they can also be misleading and end up reinforcing one's own prejudices. Confirmation bias also tends to involve critiqueaverse concepts that are not falsifiable. Ehrenreich (2017) explains that people tend to "underestimate the risks of events that unfold slowly and whose consequences are felt only over the long term (think global warming) and overestimate the likelihood of events that unfold rapidly and have immediate consequences (think terrorist attacks) (para. 11). Laypeople also tend to conflate experts' errors with systemic error, and point to instances of experts being wrong in order to reject, across the board, findings they don't agree with (T. Nichols, 2017).

Contrary to the arbitrariness that is often associated with experts, Santer (2017) recounts the thought processes involved with scientific expertise, from the perspective of being a climate scientist:

You put in a long apprenticeship. You spend years learning about the climate system, computer models of climate and climate observations. You start filling a tool kit with the statistical and mathematical methods you'll need for analyzing complex data sets. You are taught how electrical engineers detect signals embedded in noisy data. You apply those engineering insights to the detection of a human-caused warming signal buried in the natural "noise" of Earth's climate. Eventually, you learn that human activities are warming Earth's surface, and you publish this finding in peer-reviewed literature. (para. 4)

Part of this process involves extensive peer review and assessments, along with a deliberate decision to consider one's own bias, hold up a range of scientific findings against your own, and work within the limits placed by industry and government. 
On top of this careful practice, climate scientists deal with constant criticism of their findings and are held up to extremely rigorous standards. Yet their conclusions, like those of other experts, are dismissed as "opinion."

It should come as no surprise that educational institutions and professionals are the continual target of right-wing discourse opposing expertise. At a recent Trump rally, Donald Trump Jr. directed young conservatives to "keep up that fight, bring it to your schools. You don't have to be indoctrinated by these loser teachers that are trying to sell you on socialism from birth" (Mazza, 2019, para. 3). Not limiting their wrath to public schools, early $60 \%$ of Republicans see universities as negatively contributing to US society, marking the first time a majority of conservatives viewed postsecondary education in this light (Sitrin, 2017, para. 2). Trump's election and the strident anti-expertise thinking that comes with it has impacted conservatives, 54\% of them who as recently as 2015 viewed universities as having a positive impact on the country (para. 2). One contributing aspect of the backlash is the fact that Trump is actively resisted on college campuses and the loyalty aspect of anti-expertise thinking kicks in.

Jones (2015) also connects recent hostility toward teachers to an overall deprofessionalization of teaching, where teachers are expected to align themselves with the business world and "willingly agree to repeal tenure, give up collective bargaining, and accept job performance evaluation based largely on student test scores, and support merit pay" (p. 36). Jones also notes how notions about expertise surrounding the saying "those who can't do, teach" have long been a part of the teaching profession, hinting at the perceived lesser quality of teachers who couldn't survive in more prestigious professions. The irony is that the increased surveillance and rigidity of evaluation schemes paired with lower salaries and no workplace protections that conservatives advocate for would not be tolerated by higher-paid professionals.

Ultimately, anti-expertise thinking occurs against a backdrop of overall distrust of government and any kind of public service, including education. "Education reformers" and others with an interest in eroding expertise, "draw upon the economic understanding and political will of a sizable number of citizens and politicians that has taken shape since the economic downfall of 2008 and the rise of the Tea Party" (Jones, 2015, p. 9). This contributes to an attitude of "cutting the waste," the waste being experts who are blamed for social problems. Dorfman (2017) recalls more dire consequences of this line of thinking in 1973 Chile:

Books were turned to ashes, musicians were shot, scientists and educators were tortured. Meanwhile, the military, inspired by the same fundamentalism and loathing that had raged in Franco's Spain, derided intelligence and reveled in death. The intelligentsia, they insisted, was to blame for Chile's upheavals and supposed decline. (para. 3)

McCandless' (2017) investigative piece on the city of Von Ormy provides a recent case study of the consequences of rejecting expertise. Back in 2006, a few residents 
were hostile to the idea of the city becoming annexed by San Antonio as well as resistant to any solution that involved formal roles of government. The libertarian mayor, Arturo Martinez de Vara, floated the idea of Von Ormy becoming a "liberty city," essentially "a stripped-down, low-tax, low-government version of municipal government" touted by the Texas Tea Party (para. 6). According to the plan, the town would first collect property and sales taxes, but eventually the property tax would be reduced to zero.

To make up for the revenue loss, residents were promised that businesses would be attracted to the low tax base and eventually only sales taxes would be needed to support the city. Martinez de Vara attempted to recruit major chains but immediately ran into a problem because there was no sewer system in Von Ormy and connecting to San Antonio's was too expensive. The City Administrator suggested accepting a bond, which most cities do when faced with major expenses. Martinez de Vara turned down this advice since liberty cities were supposed to stand on their own without assistance.

By 2011, Texas Republicans took notice and began to tout the city as an impressive example for other smaller localities, recruiting Martinez de Vara to serve as chief of staff to Representative John Garza and later Senator Konni Burton. However, an attempt to pass Senate Bill 710, recognizing the liberty city concept as an official category of municipal government never made it out of committee. The promised businesses never materialized. By 2016, the police and fire departments had to close down. City officials ended up bickering over who was supposed to be police chief, with the new mayor attempting to fire the existing police chief who was accused of misrepresenting his law enforcement resumé. Three city council members were arrested on the assumption that they violated the Open Meetings Act and others kept things at a standstill by refusing to show up to vote for important measures. Essentially, the only thing left in the town was enough blame to go around (McCandless, 2017).

\section{PSEUDOSCIENCE}

Feeding off of anti-expertise sentiment, pseudoscience uses a different strategy by presenting itself as connected to the scientific community while using superficial markers of science as a way to obfuscate and insert confusion surrounding important public health issues. Pseudoscience practitioners use visual and discursive symbols of academic science as a way to add credibility to their messaging while supporting science in the service of capital. Currently, there are three primary approaches that are part of pseudoscience. First is the presentation of flat-out false or unscientific ideas under the guise of science. Second includes the tactic of using different means to interfere with or suppress the development and distribution of scientific knowledge. Finally, a third way that pseudoscience is promoted involves the selective support and funding of science projects that can be monetized in a capitalist system while ignoring projects for the common good. 


\section{The Guise of Science}

Regarding the first approach, Trump's election, friendliness toward white supremacists and receptivity to pseudoscientific thinking has revived debunked concepts such as race realism and evolutionary psychology, which uses academic language to carry racism, sexism, and homophobia to the mainstream. Additionally, movements like the flat earthers and anti-vaxxers often use scientific-sounding arguments to support faulty reasoning, creating just enough confusion while taking advantage of the both-sides-ism of the media. For Gaspar (2018), concepts like scientific racism, though regularly refuted, have to be repeatedly debunked because the inequality that feeds these ideas has never really gone away. In other words, "because scientific racism is driven not by scientific evidence but by the racial animus of some and the unexamined assumptions of others, these hopes have not yet come to fruition" (p. 104).

A hallmark of pseudoscience is pointing to indirect evidence that is neither refutable nor testable, such as attributing differences to specific genetic traits (Gaspar, 2018; Penny, 2018). Science often gets mixed together in a hodgepodge of religious assertions, as Penny (2018) colorfully explains:

The simultaneous appeal to both science and religious mysticism, to God-andor-genetics, is an ingenious arse-covering mechanism: if God didn't strictly say he created man to compete in a series of vicious status battles and fuck the other guy, then genetics probably did, and any blue-haired social justice neuroscientists popping up to explain that that's really not how gene expression works simply haven't grasped the larger cosmic context. If there's no actual scientific evidence for it, then it's all a metaphor. It's a prosperity gospel for toxic masculinity, The Art of the Deal via the Book of Leviticus. (para. 48)

To support pseudoscientific notions of race, past research such as the classic twin studies (where identical twins are raised separately yet have similar personality traits) are often cited (Gaspar, 2018). The problem with these studies is that the socio-environmental conditions where the twins were raised are just as identical as the twins themselves.

Gaspar (2018) notes that pseudoscience's preoccupation with genetic causation is ultimately connected to right-wing efforts to end social programs that are designed to ameliorate poverty. He presents the case of childhood asthma, which is almost entirely environmental, yet funding continues to prioritize genetic studies. Even when motivations are more positive, such as including non-white patients in medical research, they end up reinforcing flawed thinking about race and genetics. For example, white medical students often hold false beliefs about Black patients, including that they process pain differently or that their blood coagulates faster (para. 109). Likewise, despite evidence that the environment is a more significant shaper of intelligence than genetics, beliefs about biological differences in 
intelligence between whites and minorities persist in differing degrees of intensity (Hatewatch Staff, 2018).

The interconnection between white supremacist groups and race realism is represented by figures like Sam Harris and Jared Taylor, who are able to appeal to the more secular, non-religiously-based demographic known as "skeptics." On the Daily Stormer, a white supremacist website, Taylor is cited by one out of five members as having introduced them to white nationalism (Hatewatch Staff, 2018, para. 29). During one podcast, Harris used flawed data to assert that Muslim bans were rational because of their inherently violent traits and stressed that "this is not an expression of xenophobia; this is the implication of statistics" (para. 30). Similar pseudoscientific speculations are regularly broadcast on the news media to imply that immigrants from southern hemispheric nations are genetically and culturally inferior to whites, along with harboring diseases (Dorfman, 2017).

Torres (2017) explains that in communities that authentically value rationality, those who might not have the expertise tend to take a wait and see attitude when it comes to more complex scientific issues. Pseudoscientists like Sam Harris or Jordan Peterson violate this epistemic protocol by immediately declaring that characteristics related to race and gender are genetically based. In turn, they get rewarded by those in the right-wing atheist community for being bold and edgy and are in turn cited by other conservatives. Because of their atheism, they feel insulated from their views being critiqued for their religiosity, as often happens with Christian pseudoscience practitioners. Torres also sees an ethical violation in their taking up the question of the inferiority of races and genders to begin with, especially when members of those groups are often the most vulnerable to the consequences of those ideas taking hold in society as white supremacists become empowered. The irony is that by alienating women and minorities, right-wing atheists lose a significant number of allies in confronting the excesses of religiosity.

\section{Interfering with Science}

The second approach to pseudoscience involves direct interference with scientific work. This can take several forms including appointing corporate cronies to scientific posts, censorship of data that doesn't conform to right-wing policies, and harassment of scientists who work in fields that challenge profit. These strategies often occur in combination. A recent example is the Trump administration's Scott Pruitt not renewing the contracts of Environmental Protection Agency scientists involved with oversight of research and development and then replacing these positions with oil and gas industry representatives (Geiling, 2017; Dorfman, 2017). The rationale provided? "EPA advisory boards did not include a diversity of views and therefore frequently presented a biased perspective on issues before them" (para. 5). In other words, the EPA scientists were not exclusively promoting research to prop up energy companies and were therefore "biased." 
While it isn't possible to outright ban scientific research, private sector companies know that it is relatively easy in a nation with low scientific literacy (Miller, 2016) to introduce just enough industry-friendly perspectives under the guise of scientificsounding language to create confusion:

Both mistrust of scientists and other "experts" and mistrust of the mass media that reports what scientists and experts believe have increased among conservatives (but not among liberals) since the early ' 80 s. The mistrust has in part, at least, been deliberately inculcated. The fossil fuel industry publicizes studies to confuse the climate change debate; Big Pharma hides unfavorable information on drug safety and efficacy; and many schools in conservative areas teach students that evolution is "just a theory." The public is understandably confused about both the findings and methods of science. (Ehrenreich, 2017, para.7)

During the 1990s when the tobacco industry was facing increased scrutiny, Philip Morris funded the Orwellian astroturf group, The National Smokers Alliance, and distributed newsletters to cigarette consumers (Halpern, 2015, p. 8). Tobacco companies also created legal entities, the American Smoker's Rights Foundation and American Smokers Alliance used to delay the legal process and produce publications.

Scientists are also directly harassed by well-funded organizations and corporations, specifically by the use of public records laws such as the Freedom of Information Act (FOIA) (2016). These laws were originally intended to promote open inquiry and discourse on a variety of important topics and were meant to provide an important check against harmful research. Currently, they have been seized upon by conservatives as an important tactic (Kurtz, 2017). Public universities, which use taxpayer funds, are especially subject to FOIA requests (Halpern, 2015). Nearly 66\% of these requests are from private organizations with the goal of targeting researchers whose work presents a threat to their profits (p. 4). Essentially, conservatives have gone beyond using public records to gain an advantage in scientific knowledge to weaponizing FOIA. Examples that Halpern shares includes groups publishing contact information of scientists, including their home location and private phone numbers, which has led to cyber-mobbing and death threats.

A specific example that Halpern provides is the Wisconsin Republican Party using FOIA to obtain the email correspondence of a history professor, William Cronon, who was researching labor history and collective bargaining, topics hostile to Governor Scott Walker's efforts to squelch labor. Around the same time, another industry group in Michigan targeted three other professors who specialized in labor studies (p. 9). Emails have become a specific goal of conservatives because most communication now occurs in this fashion:

Snooping on researchers' emails has become the twenty-first-century equivalent of tapping their phone lines or bugging a lab's water cooler. Further, social expectations around transparency are shifting. More and more, hackers are 
illegally obtaining private information-from emails to intellectual property to credit card files-from major corporations, government agencies, and scientific institutions and disclosing it online. (p. 2)

The scope of who is targeted can also exceed the researchers themselves. Markowitz and Rosner's (2013) book on the history of industrial pollution and how chemical industries intentionally suppress environmental impact research resulted in conservatives attacking their reputation as researchers. Lawyers working for chemical companies not only legally harassed the original authors, but sent subpoenas to those who peer reviewed the book. Eventually, "industry representatives later used a FOIA request to the National Science Foundation to seek "all records relating to research conducted by David Rosner and/or Gerald Markowitz on the history of lead that has been funded by NSF" (p. 4).

These types of efforts do result in pushback by scientists and concerned citizens. Williams (2017) points to the creation of Alt-National Park Service Facebook and Twitter pages to directly share scientific information with the public as a countermeasure to the Trump administration. Large-scale marches for science occur annually, with protest signs indicating a more systemic critique of how science serves profit over people (Molteni, 2018). Another issue that people are mobilizing around is how anti-immigration policy in the form of travel bans harms science, since $20 \%$ of scientists working in the US are not native-born (Williams, 2017, p. 35).

\section{Science for Profit}

The final approach to pseudoscience is the privileging of scientific development and research with the most potential for monetization over projects that have less of an immediate profit potential. An example would be funding science in support of smaller-scale alternative energy companies or carbon tax schemes rather than putting the full weight of scientific knowledge behind confronting climate change as a whole. While not attempting to mislead or interfere with the scientific process like the first two forms of pseudoscience discussed above, this third form has larger and more dangerous implications. By failing to examine science in dialectical materialist terms, the default position remains limited by what can or can't produce profit. This starts with the funding of public universities, which has dropped to states only funding $19 \%$ of expenses and public universities receiving fewer federal grants than private ones (Halpern, 2015, p. 2).

The question of how to address pseudoscience must be approached within a dialectical materialist frame. Galileo is often held up in a limited way as an example of how new scientific ideas are penalized. Williams (2017) points out how Galileo's confrontation with the Catholic church is often presented as a matter of religion's censorship of science. In actuality, there were more far-reaching issues at play, not unlike our current era: 
Galileo's conflict with the Papacy was, in fact, just as rooted in material considerations of political power as it was with ideas about the nature of the solar system and our place within it... Under pressure from what came to be known as the Thirty Years' War raging across central Europe between Catholic and Protestant armies, Urban was attempting to shore up and re-establish the might of Rome though the Inquisition, racking up massive Papal debt from increased military spending, while promoting rampant nepotism and corruption. (p. 34)

This example is important because it highlights how science does not exist apart from social forces nor does it come down to simple binaries of "either religion or science." There are additional factors that work against science serving human need.

Advocating for science by itself is no guarantee that it will serve in the public's interest because currently the majority of scientific efforts take place within a capitalist system that prioritizes profit over human need. On the one hand, it is clear that science itself has been under attack by both religious and right-wing secular forces. Yet at the same time, science is a field that exists within a class society, so it is going to reflect the interests of the capitalist class to begin with. As Williams (2017) notes, "Trump is not telling businesses to stop doing science. He wants the federal government to stop doing science in the public interest. He wants to end fact-based discourse wherever the facts run counter to right-wing ideology" (p. 37). For Gaspar (2018), defeating pseudoscience necessitates taking on capitalism and its utilization of racism and sexism.

\section{FAKE NEWS}

On July 4, 2017, National Public Radio (NPR) continued its nearly 30-year practice of highlighting the Declaration of Independence, that year using the format of Tweeting line-by-line excerpts. Immediately, NPR was attacked on Twitter by angry Trump supporters, accusing the media organization of fomenting rebellion and spreading propaganda (Rosario, 2017). The fact that they assumed the line "A Prince, whose character is thus marked by every act which may define a Tyrant, is unfit to be the ruler of a free people" referred to Trump was telling enough, but "what leapt out...is the fact that Trump supporters are so detached from reality that they literally thought NPR was openly calling for a violent overthrow of the President of the United States" (para. 2).

Additionally, only one fourth of those who voted for Trump believe that climate change has been impacted by humans and just over $40 \%$ of Republicans acknowledge human evolution (Ehrenreich, 2017, para. 2). After the inauguration, even when shown photographs comparing Trump's and Obama's inauguration crowds, nearly 1 out of every 6 Trump voters declared that Obama's inauguration crowd was smaller (para. 3). Further edging into the terrain of the unreal, 66\% of conservatives believe that Sharia law is being practiced in US courts and just under half "either thought that 
Hillary Clinton was connected to a child sex trafficking ring run out of the basement of a pizzeria in Washington, D.C., or weren't sure if it was true" (para. 3). And for those who argue that this is just a phenomena among the less educated, "collegeeducated Republicans are actually more likely than less-educated Republicans to have believed that Barack Obama was a Muslim and that "death panels" were part of the Affordable Care Act." (Ehrenreich, 2017, para. 5).

Narayanan et al. (2018) identify five characteristics of fake news: (1) not using proper journalistic standards such as citations; (2) style that includes hyperbole, emotionally charged language, misspellings, communication via memes; (3) spreading of conspiracy theories and self-referential evidence; (4) partisan reporting, and (5) using counterfeit tactics like pretending to be an academic site. If distributed information includes three of these characteristics, it is likely to be fake news. In Starbird's (2017) analysis of fake news sites, much of the discourse was not limited to traditional political frames such as liberal/conservative, but instead floated stories related to anti-globalism (closely tied to anti-Semitic conspiracy theories) and criticisms of Western governments in general. These sites present themselves as "an alternative to mainstream media" whom they label as "fake news" (p. 9).

A general distrust in traditional media has been growing, particularly since the exposure of the manufactured evidence leading the invasion and occupation of Iraq and Afghanistan (Narayanan, 2018; Pomerantsev \& Weiss, 2014). Trump himself has made it his mission to dismantle the media, mostly as a form of revenge for it not providing non-stop positive coverage of him and his administration. This is ironic considering the free and mostly positive coverage he received during his campaign, exceeding that of any prior candidate (Kellner, 2017; Illing, 2017a).

T. Nichols (2017) also views American skepticism toward the media is part of a larger tendency to not trust anything anymore - or at the very least people more intensely distrust sources that tell them things they don't like to hear. Even though just over $60 \%$ of Americans view news organizations as inaccurate, that number is reduced to $30 \%$ when people are asked about the sources that they use the most (p. 158). National media distrust is also divided along partisan lines, with a 10/85 approval/disapproval split for Republicans, beating out labor unions which stand at 33/46 (Kilgore, 2017, para. 5). As a contrast, nearly $45 \%$ of Democrats and Independents see the media as a positive entity, an increase of 11 points since 2016 (Sitrin, 2017, para. 7).

The media itself has been the single biggest contributing factor to Trump's rise, starting with a decades-long right-wing talk radio onslaught, culminating in Fox News 24/7 echo chamber of misinformation (DeVega, 2017). Pomeranstev and Weiss (2014) see the liberal ethos of stepping back and letting the viewers make up their minds as having created a major vulnerability that the right wing eagerly exploited:

Freedom of information and expression are sacrosanct in Western culture. They are key to any idea of globalization based on liberal democracy. The more 
freedom of information we have, the thinking goes, the greater the debate, and the greater the common good. But what if a player uses the freedom of information to subvert its principles? To make debate and critical thinking impossible? Not to inform or persuade, but as a weapon? (p. 14)

Making this situation even more urgent is that the very people who see themselves as highly informed and above the fray in avoiding the mainstream media are the most receptive to fake news, representing "an abandonment of objectivity that precludes and abandonment of accuracy" (p. 35).

A key driver of fake news has been emotion, closely followed by group membership, which are prioritized over evidence. Coupled with a lack of clarity regarding the political process, people are able to now receive immediate validation on social media, "a projection of themselves" where "they're wedded to the notion that they are the peer of the person they're talking to" (DeVega, 2017, para. 24-25). Emotion and loyalty can be easily used to walk around inconvenient facts, such as evangelicals viewing Obama as the antichrist and Trump a God-fearing Christian (The Power of Groupthink, 2017, para. 10). Which attributes are prioritized is another aspect of the psychology of right-wing media, with conservatives more highly rating conformity, tradition and authority while dismissing kindness, fairness, and ambiguity as evidence of weakness (Ehrenreich, 2017).

The manipulability of emotion has not gone unnoticed. Shaw (2018) recounts the investigation into Cambridge Analytica and their use of behavioral and psychological research to influence not only elections in places like Nigeria in 2007, but the 2016 US election by distributing targeted inflammatory fake news. Global Science Research, another company associated with Cambridge Analytica, utilized an app that collected data from Facebook users via a personality quiz, under the guise of academic research. However, the app also gathered data from Facebook friends of the quiz takers, who never consented to having their data harvested. Only after it became known that Cambridge Analytica was contacted to work with the State Department and the Pentagon did the story break.

However, Shaw outlines how the connections between psychological research and warfare is nothing new:

Much of the classic, foundational research on personality, conformity, obedience, group polarization, and other such determinants of social dynamics - while ostensibly civilian - was funded during the cold war by the military and the CIA. The cold war was an ideological battle, so, naturally, research on techniques for controlling belief was considered a national security priority. (para. 6)

Other civilian programs utilizing behavioral research include the Well Being Institute, focused on developing characteristics like "resilience" and "optimism" to work hand-in-hand with big data so that employees will become more productive and 
less resistant to the neoliberal workplace (para. 11). Essentially, behavioral science is being used to prioritize the manipulability of people over fostering rationality.

Fake news is therefore the manifestation of the transformation of journalism from a profession that distributes information meant to benefit people into a form of public relations (PR) (West, 2016). This branding-focused PR is hyper-targeted toward different interest groups, a form of micro-individualism:

What once called itself a provider of news now sees itself exclusively as a platform for a plurality of (pre-approved) "voices" and identities, all marching to the beat of same consumer ethos: "do you," "be one of a kind," "be together, not the same"...where the power of something like criticism...is overtaken by the more pressing desire to confirm one's mind, one's self, as it is, and to guarantee its equal representation in the cultural and political marketplace.

(Alvarez, 2017, para. 2)

In one example, West (2016) describes an online platform Kinja, where commenters start blogs hosted by Gawker, the content of which is "mined for re-posting on the main sites" (p. 115). The fact that salaried journalists would be working alongside "the anonymous ramblings of the unpaid commentariat" (p. 116) is cause for concern but not surprising considering how there are now nearly five PR people for every one journalist in the US (Pomeranstev \& Weiss, 2014, p. 34). This, against a backdrop of a 33\% reduction in journalistic personnel since 2006 (p. 34).

The social media model for news has worked in tandem with the PR approach, especially since $67 \%$ of Americans now receive at least some of their news from platforms such as Facebook and Twitter (Shearer \& Gottfried, 2017, para. 1). While reputable news outlets are on these platforms, they are mixed in with an array of fake news sites, often incidentally popping up in the form of ads or links during a search. Narayanan (2018) notes how highly targeted algorithms used on social media platforms are able to gather information about users and the type of information they share, so it was only a matter of time until the discovery that this feature could be used for a variety of political purposes, including Russia's use of automated accounts and bots. The hyper-polarization of media discourse leading up to 2016 is locked into a cyclical relationship with the social media model which feeds the discourse, to the point where it is hard to know where it begins or ends.

Narayanan (2018) tracked the spread of computational propaganda and identified two primary distributors of fake news, the Trump Support Group and the Conservative Media Group, both with coverage rates in the mid-90\% range (p. 4). The Trump Support Group alone spread more fake news than all of the other groups reviewed put together. Far from being a "both sides do it" activity, Narayanan found that there was limited overlap between the sources that Democrats and Republicans shared on social media, with Democrats preferring mainstream media sites and Republicans preferring fake news sites. The one exception is the Occupy-related sites which have significant overlap with conspiracy-theory sites. 
A recent example of fake news cutting out the middleman is the Trump TV endeavor, in particular its purposefully Orwellian-named Real News Update series. Overseen by Lara Trump, Trump's daughter in law who once produced Inside Edition, Trump TV operates out of Trump Tower yet presents itself as a legitimate television news network (Illing, 2017a). Trump TV is supported by Trump's reelection fund and is for all intents and purposes a state-owned propaganda arm no different than those in authoritarian regimes. Illing points to the cable channel GOP TV in 1995 as an earlier example of rightwing propaganda, but whose reach was nothing like today where information is distributed openly vs. the underground networks of video cassettes in the 1990s used to recruit younger media conservatives.

The benefit of the hermeneutically closed-loop nature of Trump's base regarding the media they consume is that there appears to be no combination of actions that is enough to budge their support, with $20 \%$ of his supporters declaring unconditional loyalty (The Power of Group Think, 2017, para. 5). Further, because the Republican Party depends on this same base for political survival, they have taken no actions to censure Trump, despite the growing evidence of collusion with Russia, obstruction of justice, and fraud, let alone sexual assault (Kellner, 2017). This then sets the bar for what Trump and the GOP are able to get away with. A major contributor to the extreme loyalty of Trump's base is the construct of fake news and the projection of the fake news accusation onto any source that attempts to criticize Trump and his actions (Kilgore, 2017). Such critics are dismissed as being politically biased, even if evidence is presented, creating an impasse:

You cannot reach out and find common ground with people who do not acknowledge reality in any way. There is literally no amount of evidence that can persuade them once Fox News, AM Hate Radio and Breitbart sell them the lie. Every word Trump speaks is infallible and if he directly contradicts himself, the fake new media is guilty of taking his statements out of context. (Rosario, 2017, para. 8)

\section{BOTH-SIDES-ISM}

The centrist counterpart of fake news, both-sides-ism, advances the claim that if a liberal or leftist perspective is included in journalistic media, then other perspectives must be included for balance. This is embodied in Fox News' original motto of "fair and balanced," (which has now tellingly been dropped) the idea being that there is such a preponderance of liberal values within the media that a marginalized and powerless right wing has to endlessly struggle for survival in order to gain a hearing. Reality paints a different picture with conservative leaders of major media outlets, such as the broadcast company Sinclair, which owns the largest number of TV stations in the US (Graves, 2017).

Even in cases where the leadership of these companies and their programming may accommodate centrist or even liberal perspectives, they fully support and 
privilege capitalism and discourse friendly to it. Far from there being a clandestine conspiracy among right-wing media owners to target liberals, suppression of leftist views in the media are baked into the formula by default:

It is enough that corporate-inspired ideologies pervade a society and that corporate ownership ensures that decision-making positions are filled with those who hold to some variant of prevailing ideologies or are inclined to play it safe by cautiously remining within acceptable boundaries. The mass media will then simply reflect these dominant ideologies, and continual repetition through multiple mass-media outlets reinforces the ideologies, making them more pervasive until the emergence of a significant countervailing pressure. (Dolack, 2017b, p. 35)

The two-part rationale supporting both-sides-ism is the idea that a) all opinions are of equal weight and value and b) all opinions have the imperative to be heard. A key problem with this is the notion of automatic protective rights surrounding opinions, or the idea of entitlement to one's opinions, which "devalues the ways that opinions are supposed to earn serious consideration through logical argumentation, persuasion, rigorous research, and expertise" (Alvarez, 2017, para. 6). Within media outlets, it doesn't take long for this entitlement rationale to slip into demands to "respect" opinions, which means protecting opinions from external challenge. Because of the highly individualized nature of opinions ("it's my opinion!"), it serves as an automatic shield from critical discourse, as if those interrogating opinions are violating some sort of sacred space and veering into personal attack (Goldberg, 2018).

The pressures then mount for centrist media spaces to not be closed-minded and to find aspects of individualized opinions (that cannot be challenged) to hold up for discussion, thus giving some sort of serious weight by merely being mentioned in a publicized and prestigious format (Ganz, 2018). It's important to note that invariably these demands come from conservative groups. What ends up happening is that the news stories which prop up dominant discourses are covered more frequently and for longer time periods, thus magnifying conservative and pro-capitalist ideologies. At the same time, "stories that are ideologically inconsistent are reported briefly, often without context, then quickly dropped" (Dolack, 2017b, p. 35). It then becomes easier for both-sides-ism to reinforce right-wing views under the veneer of an open and tolerant democratic ethos, which gives it deeper cover.

This is illustrated by the actions of the Atlantic magazine's recent hire of anti-choice advocate Kevin Williamson, who advocated abortion be treated as premeditated homicide. Though eventually fired after public outcry, the idea that a mainstream outlet would feel pressured to incorporate someone with Williamson's views when there are many conservative media outlets available to him is troubling (Goldberg, 2018). The blurred lines and deliberate destabilization generated by fake news and its insertion of doubt has apparently hit moderate outlets who seem incapable of reaching a basic level of consensus. 
Alvarez (2017) presents an overview of other mainstream elite outlets like the New York Times who hired climate-change denier Bret Stephens as a regular columnist. A frightening rationale for hiring Stephens was provided by the Times' editorial page editor, who claimed "there are millions of people who agree with him" (para. 13). CNN used a similar justification for hiring commentators Jeffery Lord and Corey Lewandowski because of their "expertise." Alvarez concludes:

In one sense, it's baldly a question of money and ratings - news outlets maximize their chances of drawing in bigger audiences by giving platforms to a more "diverse" range of opinions. In another sense, though, this rationale takes for granted that the job of a news outlet is not so much to present consumers with "truth" as to represent an array of rigid viewpoints with which consumers can potentially identify. (para. 13)

However, media consumers can fight back in a big way. In October 2018, The New York Review of Books (NYRB) decided to publish an essay by Jian Ghomeshi, a Canadian broadcaster who was accused, and later acquitted, of seven counts of sexual assault, including choking, by several women (Gollom, 2016). The essay appeared without any accompanying information about the charges or responses from any of the women who had accused him. In the essay, Ghomeshi (2018) briefly summarizes how he was accused of "criminal charges including hair-pulling, hitting during intimacy in one instance, and - the most serious allegation-non-consensual choking while making out with a woman on a date in 2002" (p. 29). That pretty much ends any mention of his actions as he proceeds to go into a litany of rationalizing, free from the constraints of any sort of counter-perspective, which is how both-sides journalism actually operates.

Referencing his celebrity status, Ghomesh and that "I was the guy everyone hated first" (p. 29). Ghomeshi then dismisses the importance of public apology because he himself had always doubted other men who had publicly apologized after being accused, and because the response to being accused of sexual assault is too allencompassing to really be able to sincerely atone in that manner. He also explains how apologies are not a reliable way to ensure the whole mess gets turned around in one's favor: "What you truly fear in the first days after being publicly accused is fear and anger, in that order" (p. 29). If the apology could make the whole thing go away, then it might be a worthwhile thing to do.

What is remarkable is how, over several paragraphs, Ghomeshi proceeds to detail his suffering, such as being afraid to leave the house, losing friends, being attacked online, and stereotyped with other rapists. This entire account is made rhetorically possible by his brief and breezy dismissal of the accounts of the women involved early on in the essay. Their absence makes his essay plausible at first glance. Immediately, he pivots to his supporters, who over time, are less likely to vouch for him: "as the storm grew, many backed away, too scared or conflicted or shocked at the headlines to make a public stand" (p. 30). The phrase "as the storm grew" is more accurately a stand-in for his female friends probably reading the actual testimony 
from several women and having second thoughts, not so much them being afraid or shocked at the scandal itself as he claims.

The essay ends with Ghomeshi describing an anonymous conversation he had with a woman on a train about music. His account has him resisting impulses to tell her about his notoriety, the overall message being "she just liked me for ME and not because of my fame." The reader is apparently supposed to be impressed that he didn't give in to his former ways and has now reformed. What is the most striking about Ghomeshi and others like him is the expectation that they should not only continue to have a normal life, but also get to parlay their experiences into a revival of their careers, with a nice glossing over of the women involved and a silencing of their voices. The media is a direct partner in these efforts.

After facing an outcry by regular subscribers, feminist groups, and academics, The NYRB published an extensive "letters to the editor" section in the following issue, thinking that would hold back the heat. Taken together, these letters serve as a critical corrective to the account Ghomeshi provides and reveals both-sides-ism for the hollow farce that it is. The reader is immediately struck by the collective characteristic of the writing in the letters, far exceeding the quality of Ghomeshi's essay. Collectively, the letter writers made it clear that this goes way beyond a free speech issue (as it is often reduced to), but an issue of editorial discretion, considering that publications do not have to print everything they receive, as Meghan G.'s response summarizes:

By publishing this, you are telling us that the people who violated us can get away with it, relatively unscathed. Hell, they can even write an article about the difficulty of leaving the house post-persecution. You tell us that our security, safety, and lives mean less than those who harmed us. (Responses, 2018, p. 58)

One of the best letters was written by Joanne O., who was victimized by Ghomeshi in 2013. She viewed the decision to publish his essay as having consequences reaching far beyond just telling his side of the story. By a respected publication such as the NYRB giving legitimacy to Ghomeshi and not including any contextual information, it served as a public reminder that his story would be believed, and the victims' accounts wouldn't. His story was therefore worth more as well as getting a double hearing, the first being in court. Joanne then took on the usual media tactic of questioning women's own experiences with sexual assault and the notion of them imagining things:

My experience is so similar to other women's you may think we must have colluded. But no, we don't have to speak to one another to know how this reality feels because this reality is so common for far too many of us...our stories are rarely ever heard beyond a sensational article in which we rip ourselves open to expose our wounds for the salacious reader. (Responses, 2018, p. 54)

Linda Redgrave, another letter writer, notes how Ghomeshi's essay may have been an attempt on his part to put a career back together, but that it is not sufficient and he 
now must face "the court of public opinion" which is "a very large court, and we are trauma-informed judges” (Responses, 2018, p. 54).

Since the NYRB wasn't able to do some basic journalistic follow-up on the essay's claims, Lisa Guenther's letter stepped up to the task:

The fact that you published Ghomeshi's point of view on the numerous allegations against him without minimal fact-checking is reprehensible. For one thing, he was not fired by the $\mathrm{CBC}$ because of "allegations circulated online" by an ex. He was fired because he literally showed CBC brass photos of a woman he had beat the hell out of, and tried to pass it off as "rough sex." $\mathrm{Oh}$, and there are no such things as charges of hair-pulling, etc., not even in Canada. (Responses, 2018, p. 54)

One letter writer, Lester Bergquist, simply quoted an excerpt from the trial transcripts of one of the victims, letting the account speak for itself: 'I'm terrified. I don't know why he's doing this, I don't know if he's going to stop...And my ears are ringing, and I felt like I was going to faint. I'm going to end up passed out on his floor" (Responses, 2018, p. 56).

Some readers extended their critique of the essay's publication to the larger systemic lack of diversity of the NYRB, connecting the decision to publish the essay with the idea that even a mediocre essay from a male celebrity broadcaster is more important than the voices of women and minorities. Rohan Maitzen takes on the common tactic of an organization referencing their "quality" standards as a rationale for not having diverse writers. If "quality" was the primary criteria driving the decision to publish, then how to explain the NYRB publishing such a mediocre essay?

Diversity is an aspect of quality, and the apparent recalcitrance of the NYRB's editors in the face of reasonable pressure to feature a wider range of voices in its prestigious pages has been an ongoing disappointment...that you have room for his story but are indifferent to the lack of wider representation in your pages is frankly shocking to me. (Responses, 2018, p. 58)

Elizabeth Wurtzel wrote to suggest that instead of just sitting back and waiting for women and minorities to magically appear, the editorial staff needs to be actively seeking them out, including mentoring up-and-coming writers. Other letters also echoed continued disappointment at the publication not featuring diverse writers and more inclusive perspectives.

Taken together, the letters provide a damning critique of the both-sides-ism of today's press and how people are beginning to speak back against it. In particular, Bridget V.'s response takes aim at the social media model of reporting in its eroding public journalism while upholding edginess as the supreme value:

Perhaps this piece is tailored to appeal to an imagined readership of intellectually lazy men looking to indulge their narcissism. Maybe it's for the thousands of 
rage-clicks readers will inevitably give you to see what this trash pile consists of. Maybe you truly and honestly think you're showcasing a subversive new perspective on a subject. Regardless, you're reinforcing the notion that men who abuse women still have a place in their professional field. (Responses, 2018, p. 55)

Similarly, Leanna Brodie's letter posed some wry questions regarding the intellectual laziness that is both-sides-ism:

Can we expect an upcoming guest editorial from Harvey Weinstein on the art of pitching woo; the cops who beat Rodney King on their contributions to the civil rights movement; or Kevin Spacey swearing that from now on he will always check ID? Or can we agree that widely known sexual predators and the beneficiaries of miscarriages of justice have forfeited the public perks of celebrity, as well as the considerable prestige of your publication? (Responses, 2018, p. 56)

Building on this, Elizabeth Wurtzel declares "no, men do not have a side in this. That is like white supremacists saying white lives matter too" (Responses, 2018, p. 57). When one thinks about the amount of time wasted parsing the basic boundaries of what is considered "up for debate," one starts to realize the deliberateness of keeping people mired in such enterprises. Maybe it is time for centrist and liberal media to stop doing the right wing's work for them.

\section{CONSPIRACY THEORIES}

Defining what constitutes a conspiracy theory, let alone determining which are or are not legitimate conspiracy theories, has been a source of ongoing disagreement. Since this section is primarily focused on the political and personal functions of conspiracy theories as part of a larger capitalist effort to destabilize social institutions, a basic definition can be helpful. Sunstein and Vermeule (2009) conceptualize conspiracy theories as "an effort to explain some event or practice by reference to the machinations of powerful people, who attempt to conceal their role (at least until their aims are accomplished)" (p. 205). This is echoed by Ellis' (2018) definition of conspiracy theories as "an unfounded, deeply held alternative explanation for how things are - often invoking some shadowy, malevolent force masterminding the coverup" (para. 2). The unfounded component is critical because this differentiates conspiracy discourse from actual documented events of the powerful operating in often protected or concealed ways to harm the powerless, as in governmentsponsored medical and military projects.

There is no doubt that conspiracy discourse has become increasingly mainstream, especially as distributed through the media. Figures such as Curt Schilling and Roseanne Barr regularly post conspiracy theories on social media and in televised interviews. Fox News' Sean Hannity and Alex Jones weave conspiracy theories into 
their discussions of current events (Chang, 2018). Republican politicians regularly distribute conspiracy theories as current events talking points, including former Trump administration national security advisor Michael Flynn who made conspiracy theories a regular part of his communication, "ranging from stories that Hillary Clinton "is involved with child sex trafficking and has secretly waged war on the Catholic Church, as well as charges that Obama is a 'jihadi' who 'laundered' money for Muslim terrorists" (Kellner, 2017, p. 69). Of course, Trump himself is one of the most prolific conspiracy distributors, considering the power of his political office and use of Twitter. The "birther" conspiracy theory-that President Obama could not produce a birth certificate documenting his US citizenship — was a key factor leading to Trump's candidacy for president.

Of all of the strategies of the right discussed so far, conspiracy theories present the most challenging to dislodge. Part of this is due to the features built into the structure of conspiracy narratives, which requires three interconnected elements of vastness (too big to comprehend, but not to speculate on), multi-level infiltration (they are all in on it), and a sense of urgency (if we don't reveal the conspiracy, their plan will succeed) (Kimmel, 2017). This relates to Muirhead and Rosenbulm's (2018) conceptualization of "conspiracism," which is an apt term for describing a worldview as well as the overall practice of integrating conspiracy theories into all aspects of public life. They acknowledge that while the practice of conspiracism has been seen before, "the conspiracism we see today does introduce something newconspiracy without the theory" (para. 2).

In its more mainstream networks of adherents, conspiracy without the theory is more about innuendo and less about complicated narratives that one might see from more dedicated adherents (Muirhead \& Rosenblum, 2018). The phrase "people are saying" is a way to safely distance one's self from originating or taking part in the narrative: "The manner of coy insinuation that marks the new conspiracism both absolves the speaker of responsibility for the charge he's putting forth and invites endless investigation" (para.10). For example, when the political usefulness of the birther conspiracy expired, a new talking point emerged on the right that it was Hillary Clinton who originated the birth certificate story, not Trump (Prokop, 2016).

Conspiracism is also a form of conspiracy for its own sake and serves different aims, such as the birther movement seeking to delegitimize Obama's presidency or interrupting climate science work by claiming that government climate data is made up to enhance the urgency of global warming (Muirhead \& Rosenblum, 2018). This illustrates that conspiracy theory adherents have existing political beliefs that seek out self-affirming conspiracy narratives. For example, Trump supporters unequivocally reject actual acts of collusion, such as energy companies suppressing research that illustrates their role in climate change. When given a choice between two narratives, one of which has energy companies being motivated to suppress climate science because of potential profit loss or a group of climate scientists banding together to seek fame, the former narrative is rejected in favor of the latter conspiracy theory. 
In particular, after 9/11, conspiracy discourse intensified its right-wing talking points to create a special sub-category known as "conspiranoia" (Weinberg, 2010, para. 6). This resembles the constructs of superstition, which is rife with confirmation bias and common-sense notions that are difficult to disprove through traditional means (T. Nichols, 2017). As T. Nichols explains, "each rejoinder or contradiction only produces a more complicated theory. Conspiracy theorists manipulate all tangible evidence to fit their explanation, but worse, they will also point to the absence of evidence as even stronger confirmation" (p. 55). In other words, the only thing that can defeat a conspiracy theory is a bigger conspiracy theory.

In the past, the potential reach of conspiracy theories was limited to brochures, books, video recordings and public talks. There was also more of an underground element to conspiracy theories, where tight-knit groups would form to share evidence (Ellis, 2018). With the advent of social media, conspiracy theories have added to the issue of increased reach an important participatory element, which further binds proponents to the narrative as it evolves over time. In some cases, older conspiracy theories, like UFOs or the Kennedy assassination, can find renewed interest by the ability of adherents to archive publicly available materials on websites and blogs. These can then be linked to and shared quite easily.

Several websites devoted to the distribution of conspiracy theories include beforeitsnews.com, nodisifo.com and veteranstoday.com and these are linked to Twitter posts, often generated by bots (Westneat, 2017). This creates "strange clusters of wild conspiracy talk, when mapped, point to an emerging alternative media ecosystem on the web of surprising power and reach" (para. 10). As one example, Alex Jones Infowars.com has the same number of page views as the Chicago Tribune (para. 13). What ends up happening is that a person visiting these websites sees the same conspiracy theory referred to by different sites and in different forms, which gives it "the false appearance of source diversity" (Starbird, 2017, p. 9).

There are two aspects to conspiracy theories that are important to examine. The first is the political function of conspiracy theories, or that the spread of these narratives assists the ruling class in various ways. This is often uncovered through noting the common themes or threads that run through conspiracy discourse, which "pretends to own reality" while carrying us "beyond partisan polarization to epistemic polarization, so that Americans are in conflict about nothing less than what it means to know something" (Muirhead \& Rosenblum, 2018, para. 12).

A second key aspect is the personal enhancement that conspiracy theories offer to proponents. This includes a sense of participating in a conspiracy narrative as it unfolds, made possible by social media and the Internet as well as the concept that you are "in the know" unlike the rest of the population who unquestioningly follow along. It is important to note that both of these larger aspects regularly interact with each other and never occur in isolation. For the conspiracy theory to have power, it has to have both political and personal functions. 


\section{Political Functions}

Far from being relegated to the fringe, conspiracy theories have important political functions that help to propel and make mainstream anti-expertise and fake news narratives. These functions are part of conceptualizing all of history itself through the lens of conspiracy rather than understanding that "it is political economy, not conspiracy theory, that explains what is fundamentally wrong with society" (Weinberg, 2010, para. 1). The first political function of conspiracy theories is that by serving up the target of the "big entity" - whether it is a powerful wealthy person, group of wealthy people (often Jewish), multinational corporation, or government - this serves to conveniently take the pressure off of capitalism and its functions. Weinberg views conspiracy theories as serving a compensatory function, much as fascism giving "the little man" superficial changes or scapegoats instead of fundamentally confronting oppression.

The big entity can be utilized in various ways. With events like the Boston Marathon bombing, airline disasters or mass shootings where causation is pretty clear, more elaborate rumors immediately surface assigning blame to those other than the perpetrators in order to create the false flag or crisis actor type of conspiracy narrative (Starbird, 2017). This delegitimizes efforts like legislation controlling access to lethal firearms or associate liberals or the Democratic Party with terrorist activities. Another political function of the big entity is that it serves to divert attention to more fringe groups like the Illuminati or Trilateral Commission rather than the larger military infrastructure or capitalism (Weinberg, 2010). This is different than traditional notions of propaganda which is to shape thinking around a specific topic. The idea of the big entity is "to keep the viewer hooked and distracted, passive and paranoid, rather than agitated to action” (Pomeranstev \& Weiss, 2014, p. 11).

A second political characteristic of conspiracy theories is their attack on the global, usually partnered with classic anti-Semitic talking points such as the Rothschilds, Protocols of the Elders of Zion and, more recently, George Soros. It is important to note that the anti-globalization sentiment of these conspiracy narratives is always bounded by the "big entity" and never moves toward a critique of capitalism, other than to add descriptors like "global capitalism," as if the problem is its international status or multiculturalism. Westneat (2017) finds that anti-globalist conspiracy theory adherents are also "anti-mainstream media, anti-immigration, anti-science, anti-US government, and anti-European Union" (para. 20). Trump continually uses anti-globalist talking points in order to cement connections with his nationalist base (Muirhead \& Rosenbulm, 2018).

As with the big entity, anti-globalization serves to divert attention from capitalism's role in the current economic condition. For example, almost one third of people in the US think a global elite is attempting to take over the world, with $15 \%$ believing that the government, working in tandem with this global elite, has installed mind-controlling devices into televisions and broadcasts (T. Nichols, 2017 , p. 59). For these individuals, the problem isn't capitalism, it is that a small 
number of Jewish elites are attempting to take over. Weinberg (2010) notes how the conspiracy theory of history has right wing nationalistic and xenophobic roots going back the 18th century and continuing through The Protocols of the Elders of Zion, and eventually adopted by Hitler. The same can be said for anti-Muslim conspiracy theories emerging after 9/11 and The Money Masters DVD which exposes a cabal of international bankers. Most anti-globalist conspiracy theory sites never fail to track George Soros and the Rothschilds, more recently connecting them to global pedophile rings (Starbird, 2017).

Third, related to the attack on the global is the messaging of distrust in "big government" or any type of structural social program. Instead, the emphasis is on individual, isolationist, and nationalist solutions. Again, this helps to take the focus off of capitalism and place it onto efforts to support politicians who advocate for dismantling the social safety net. It is pretty easy to see how this serves as a major benefit to the capitalist class, since "the ultimate consequence of the new conspiracism is the destruction of the administrative state, a state with the capacity to design and implement long-term policy" (Muirhead \& Rosenblum, 2018, para. 13). Conspiracy theories serve to "obscure any perception of governmental integrity" and "feeds the assumption that the government is staffed by those who are actively hostile to the common interest" (para. 13). In terms of partisan politics, the majority of big government conspiracy theories attempt to tie the Democratic Party to efforts to allow minorities to take over, as in the notion that undocumented immigrants are voting in large numbers.

The fourth political characteristic of conspiracy theories is to foster a hostility toward experts, specifically around important issues of public health, climate, education, and science. Conspiracy theories also help promote a distrust in the media, with everything except the conspiracy narrative viewed as "fake news" or being in on the coverup:

The effect of conspiratorial thinking... is delegitimation. The new conspiracist accusations seek not only to unmask and disempower those they accuse but to deny their standing to argue, explain, persuade, and decide. Conspiracism rejects their authority. In the end, the consequences of delegitimation are not targeted or discrete but encompassing. (Muirhead \& Rosenblum, para. 8)

This has been assisted by the decline in the number of professionally trained journalists and "the work of gatekeeping shifting to end-users" (Starbird, 2017, p. 2). Profit-driven social media information distribution models have become conduits for content, which has "challenged the traditional authority of journalists, both directly and indirectly" (p. 2).

An additional outcome of hostility toward expertise is evidenced by the inability of the mainstream media to intervene by fact checking or other forms of debunking conspiracy narratives. Within the conspiracy mindset, fact checks only serve to further adhere followers to the conspiracy narrative: if the media is debunking us, then what we believe must be true (Westneat, 2017). This provides "the ultimate 
bulwark against expertise" because any knowledgeable professional is automatically a part of the larger conspiracy (T. Nichols, 2017). At the same time, mainstream media are referred to for evidence in support of the conspiracy narrative when the opportunity arises (Starbird, 2017). Oxenham (2017) found that the only way to counteract conspiracy thinking was to "inoculate" people with more rational assertions prior to them being exposed to conspiracy theories, "before they have the opportunity to take hold in the wild" (para. 7).

\section{Personal Functions}

Though powerful enough on their own, the political functions of conspiracy theories do not by themselves serve as a sufficient means of attracting and retaining adherents. There also have to be aspects of the conspiracy theory experience that personally bonds proponents to the narrative and to its further distribution and construction. This is incredibly important as the conspiracy discourse descends further into the realm of implausibility. You have to have such a degree of loyalty to the narrative that it approaches religious fervor in order to sustain it:

Paranoid politics is thus a psychological disposition — projecting one's problem onto the fiendish machinations of others, so as both to uphold one's own purity and goodness and simultaneously to identify the source of the problem. As with many projects that rely on psychological displacement, the groups often produce the very thing the most fear. (Kimmel, 2017, p. 230)

The first key personal function is the participatory nature of conspiracy theories, especially within the context of social media where responses to one's contributions can happen in a fraction of a second. Chang (2018) and Starbird's (2017) tracking of online conspiracy networks is invaluable in understanding the relevance of participation. In particular, Chang (2018) examines the QAnon conspiracy cascade (Sunstein \& Vermuele, 2009), which emerged in cyberspace. Essentially, proponents of QAnon assert that both Trump and Robert Mueller are collaborating to reveal a group of pedophiles that are funded by the Democratic party. Chang (2018) traces the narrative to a poster on 4chan who claimed to have "Q-level security clearance" and became known as simply "Q." Eventually, conversation about the conspiracy moved to the/r/greatawakening subreddit where participation jumped.

Because of his obvious need for anonymity, Q would post vague statements that kept the online community constantly speculating, such as telling posters "to follow former Clinton staffer Huma Abedin and to figure out why billionaire George Soros donated all his money recently" (Chang, 2018, para. 23). These and other "bread crumbs" would become increasingly cryptic and mysterious, leaving the subreddit community (known as "bakers") to be the ones to propel the narrative. As Chang explains, "this community...has turned an internet conspiracy theory into a liveaction role-playing game. They are the main characters - except they don't think it's a game; they believe this conspiracy is real" (para. 15). As the participation 
reached a fever pitch, QAnon proponents compared themselves to the reporters who broke the pedophilia story about the Catholic Church.

Eventually, Trump supporters appeared at his rallies wearing QAnon t-shirts, prompting further investigation of the conspiracy theory. Chang (2018) and his associates conducted a cyber content analysis to track the network of $/ \mathrm{r}$ / greatawakening users and found that the majority of them were not hard-core adherents. In other words, support for Trump is what drove them to participate in the QAnon conspiracy, along with other factors like cryptocurrency, men's rights, and martial arts, often associated with white males (para. 10). The bulk of the content was generated by only one fourth of the commenters, or about 200 posters (para. 11). Chang found that 700 other users contributed another fourth of the comments. The rest of the participants on the subredit (11,000 commenters/42,000 lurkers) were just "along for the ride" (para. 12).

Starbird (2017) gathered conspiracy theory tweets on Twitter, focusing on mass shootings. The research group then tweeted the URLs of the stories to recreate a quantitative visual of the network accompanied by a qualitative analysis of the different themes that arose from the networks. Results indicated that conspiracy theory adherents build connections across different conspiracy sites "in a mutually reinforcing manner," such as retweeting sites that reinforced existing political beliefs (p. 5). Additionally, much of the retweeted material was attributed to bots, with the most activity around The Real Strategy, a fake news site: "The temporal signature of tweets citing this domain reveals a consistent pattern of coordinated bursts of activity at regular intervals generated by 200 accounts that appear to be connected to each other... and coordinated through an external tool" (Starbird, 2017, pp. 5-6).

A second personal function of conspiracy narratives is the allure of being among the few who are "in the know." Being in the know serves to set you and your fellow adherents apart from the masses of people who are duped into believing what the government or other big entity wants you to believe. DeVega's (2017) interview with Tom, a conspiracy theory adherent, reveals this enjoyment of conspiracy narratives:

Yes - they are fun. Yes - it's empowering. It tells you that you are one of the people who has the secret knowledge of what is really going on. It makes you feel superior to other people. It makes you feel good; it's self-actualization. (DeVega, 2017, para. 21)

This form of wheel spinning is of enormous benefit to the capitalist class because to them, nothing is better than people being kept safely tucked away thinking they are "in the know" when all along they are happily accomplishing their work for them.

One study involving 238 participants from the US completed a survey that measured their "need for uniqueness" by indicating the degree to which they agreed or disagreed with various statements (Oxenham, 2017, para. 2). After completing the instrument, participants noted which common online conspiracy theories they believed in from a list of 99 possibilities. Researchers found that belief in one conspiracy 
theory was correlated with beliefs in others as well as a stronger endorsement of the conspiracy theories correlated with a need for uniqueness (para. 2).

In one of the more dramatic examples of the need to be in the know, an experiment was conducted where researchers made up a conspiracy theory related to smoke detectors creating a dangerous hard-to-detect sound (Oxenham, 2017). Half of the participants were told that over $80 \%$ of Germans believed in the conspiracy with the other half of participants told that over $80 \%$ doubted the theory (para. 4). Just knowing the conspiracy theory was popular tended to impact the strength of the belief of those prone to conspiracy narratives:

Their belief in the made-up smoke detector conspiracy was enhanced on average when the conspiracy was framed as a minority opinion. Just as people are known to stop liking a band as soon as it becomes popular or "mainstream," it appears conspiracy theorists can behave in a very similar fashion upon learning about the next big new conspiracy theory. (para. 5)

A final revealing finding occurred after the participants were debriefed by the researchers about the conspiracy theory being created for the study. One fourth of the participants refused to recognize that the theory was researcher-generated and became even more attached to it, rejecting all efforts to convince them otherwise.

The third personal function of conspiracy theories is they provide proponents with a sense of being in control and channel the desire to bring order to chaos through the conspiracy narrative (T. Nichols, 2017). For this reason, conspiracy theories tend to intensify during times of great historical and political upheaval (DeVega, 2017; Sunstein \& Vermeule, 2009). Because the large, imposing problems facing neoliberal society can often cause a sense of helplessness, the conspiracy theory provides a sense of relief because you can finally "see it all" and structure some semblance of order to chaos. This can go in both optimistic and pessimistic directions:

When conspiracists attribute intention where in fact there is only accident and coincidence, reject authoritative standards of evidence and falsifiability, and seal themselves off from any form of correction, their conspiracism can seem like a form of paranoia - a delusional insistence that one is the victim of a hostile world. (Muirhead \& Rosenblum, 2018, para. 6)

Of course, the irony is that the real, evidence-based problems that are happening within capitalism are totally rejected in favor of an alternative narrative that will never really address the situation. This, too, benefits the capitalist class because instead of taking to the streets in mass actions that could change things, that energy is spent on further refining and adding details to the conspiracy theory's tenets. Ultimately, conspiracy theories also take the energy that could be spent developing dialectical materialist skepticism and channels it into unproductive, formless skepticism that discourages acting on knowledge to change the status quo. 


\section{CONCLUSION}

While nowhere near the dangerous levels of nationalism that countries such as Brazil are experiencing, we can safely say that the United States is currently in the grips of direct, sustained attacks on reason, knowledge, and the notion of truth (Dorfman, 2017). The hostility toward facts and lack of critical thinking we currently see reflects a profound failure of schools to educate for the protection of democracy, in a time when no one appears to be able to hold Trump and his administration accountable (Kellner, 2017). Ganz (2018) speculates that the historical era that we are in could easily be called the Age of the Charlatan:

Everywhere you turn there seems to be some kind of quack or confidence man catering to an eager audience: Fox News hosts like Sean Hannity have moved from pushing ill-informed opinion to flat-out conspiracy mongering; pickup artists sell "tried and true" methods for isolated young men to seduce women; and sophists pass off stale pedantries as dark and radical thought, selling millions of books in the process. (para. 1)

The attraction to charlatans and what they offer seems to happen during times of immense change, when it is more challenging to handle the sheer amount of information appearing at any given time. Fake news and conspiracy theories provide convenient narratives that self-reinforce existing political beliefs and notions of common sense, along with providing the illusion that we are taking action.

When feelings become the barometer for truth, dangerous things can happen. This is especially the case where the feelings of those in power and their supporters are prioritized. For example, Trump's Tweets continuously validate the feelings of white males who are troubled by women and minorities refusing to stay quietly tucked away. As Penny (2018) points out, "Just because young white men are experiencing hurt feelings does not make those hurt feelings rational, or reasonable, or a sound basis for policy-making. It certainly doesn't oblige anyone to dignify those hurt feelings with the status of cosmic wisdom" (para. 36).

It is pretty obvious that finding a way out is going to be a challenge, especially when the ruling class has unprecedented access to the media and routinely uses strategies like fake news, both-sides-ism, pseudoscience, and conspiracy theories. The deployment of these attacks has real consequences, especially for the Earth's climate, where capitalists "can deny, delay, defund, distort, dismantle" and "fiddle while the planet burns" (Santer, 2017, para. 10). We are going to have to mobilize, and before we do, we have to face some important dialectical truths:

There are a number of claims circulating in political culture with no basis in reality that are persuasive nonetheless. They are largely impervious to challenges based on empirical evidence...the left, armed with science, history, and buckets full of facts, attempts to speak truth to power. In other words, we 


\section{CHAPTER 7}

assume that in any controversy, the person who has the truth on their side will eventually win the day. Here's the uncomfortable part: this assumption is just not true. The truth does not necessarily set us free; indeed, the powerful often control the circulation and authority of what counts as truth. (Cloud, 2018, para. 15) 